\title{
Combining Fuzzy MCDM with BSC Approach in Performance Evaluation of Iranian Private Banking Sector
}

\author{
Meysam Shaverdi, ${ }^{1}$ Mahsa Akbari, ${ }^{1}$ and Saeed Fallah Tafti ${ }^{2}$ \\ ${ }^{1}$ Department of management, Ilam branch, Islamic Azad University, Ilam, Iran \\ ${ }^{2}$ Department of management, Tarbiat Modares University, Tehran, Iran \\ Correspondence should be addressed to Mahsa Akbari, akbari.mahsa@gmail.com
}

Received 28 March 2011; Revised 21 May 2011; Accepted 5 June 2011

Academic Editor: Salvatore Sessa

Copyright (C) 2011 Meysam Shaverdi et al. This is an open access article distributed under the Creative Commons Attribution License, which permits unrestricted use, distribution, and reproduction in any medium, provided the original work is properly cited.

\begin{abstract}
The objective of this study is to construct an approach based on multiple criteria decision making (MCDM) and balanced scorecard (BSC) for evaluating performance for three nongovernmental Iranian's banks. Following the literature relating to banking performance and BSC concepts, experts and managers select 21 indexes for evaluation. Furthermore, fuzzy analytic hierarchy process (FAHP) calculated the relative weights of each chosen index in order to tolerate vagueness and ambiguity of information, and three MCDM analytical tools (TOPSIS, VIKOR, and ELECTRE) were adopted to rank the banking performance. The results indicate that a customer " $C$ " has the most significant BSC perspectives and the customer satisfaction " $C_{1}$ " is the most major index in banking sector. This proposed fuzzy MCDM method combined with BSC approach is a comprehensive and up-todate model that can be a useful and effective assessment tool.
\end{abstract}

\section{Introduction}

In today's competitive world, only the companies that observe the needs of their customers and provide them with satisfaction, can compete with others and gain benefit. This requirement causes the loyalty of customers to products and services of that organization or company. Also, bank as an organization that plays an important role in the economical development and blooming of the country must do some robust steps to assess the needs of its customers in the services which provide for them. To galvanize competition among banks, more emphasis is necessary to be put on the internal operational performance. This equals a need for finding an effective way to evaluate the performance of the entire organization to its objectives. The model presented aims at evaluating the general performance of banking which is a key factor in banking studies. Many researches are faced with financial factors to evaluate banking performance.

Recently, considerations and attentions to nonfinancial factors are increasing. Many indexes in current studies are repetitive and in some cases they were not identified. This paper not only considers new and practical indexes but also determines significant ranking for these indexes. We proposed a new and comprehensive model that can be a useful and effective assessment tool for business enterprise.

Nowadays many organizations employ numerous theories and methods of evaluation for assessment in their departments. These approaches consist of ratio analysis, total production analysis, regression analysis, Delphi analysis, balanced scorecard (BSC), analytic hierarchy process (AHP), data envelopment analysis (DEA), and so forth. Each method has its own principles, prospects and flaws [1]. Managers select this kind of method depending on the level and type of organization. Anyway, all successful organizations have common characteristics as specific outlook, positive actions and effective performance assessment. BSC is the expanded tool for assessing the performance, which acceptably programs and controls the organization to attain its goals [24]. BSC breaks down the conventional financial restrictions and assesses the performance of the organization from four perspectives: financial, customer, internal business process, and learning and growth [5]. To get to the best possible result, it is necessary to adapt the banking relations to the customer needs [6]. Therefore, experts and managers use a BSC framework for expanding the evaluative guidelines of the banking performance [7-9]. 
Bellman and Zadeh [10] developed the theory of decision behaviour in a fuzzy environment. Scientists developed many models and employed them in such different fields as control engineering, artificial intelligence, management science, and multi criteria decision making (MCDM). The concept of integrating the fuzzy logic and MCDM leads to the Fuzzy MCDM. Many academic and practical works have been done in applying MCDM to assessing criteria and selecting options [11-19]. With respect to other methods, BSC criterion is more concrete and comprehensive. In this research, the fuzzy MCDM approach is based on the above four perspectives of the BSC to create a model for assessing the performance of banking organizations. Our aims are fourfold: (1) specificity of the performance indexes in banks to create a hierarchical framework for performance assessment. (2) Usage of the Fuzzy AHP to find out the fuzzy value of indexes based on mental judgment. (3) Usage of TOPSIS, VIKOR, and ELECTRE for rating the performance of three banks. (4) Suggestions based on the outcome of the study for assessing performance. The structure of the paper is as follows: In Section 1 we introduce the concepts of performance assessment and BSC. in Section 2 we review the literature and in Section 3 we employ framework for performance assessment in analytic methods and we use the Fuzzy MCDM for assessing the banking performance. In Section 4 we explain the practical usage for assessing the banking performance consisting of the BSC hierarchical framework of assessment indexes and to present data analysis and discussion. Section 5 is conclusive.

\section{Performance Evaluation and BSC}

In this section, the paper briefly reviews some relevant concepts as the performance evaluation index and the BSC.

2.1. Defining Performance Evaluation. DuPont and General Motors designed the first systems of evaluating trade based on financial index in 1920s. Both companies had decentralized their unit benefits and synchronically considered their capital return to evaluate the financial performance of their units. Ralph Cordinerz, the senior executive director of General Electric, unveiled his dissatisfaction with such kinds of systems in 1951. This action ameliorated the general replication and the equilibrium between the short-term and long-term goals along with the profitability, market share, efficiency, and the workers' satisfaction [20]. There is a great deal of literature on performance assessment and successful performance management [21]. The traditional rating of performance was based on rigid factors as financial return, capital return, and benefit return. However, this method of performance rating cannot precisely define companies for applying the aforementioned approach [21]. Assessing the performance of a bank can be both uncertain and contradictory [9]. Previous studies on performance evaluation have examined the scale economy and employed the traditional statistical methods such as correlation analysis [22], translog cost function [23, 24], loglinear models, or the Data Envelopment Analysis (DEA) method $[25,26]$.
2.2. Performance Evaluation Index. The experts have defined the performance measurement as a control system in any company which investigates its daily operations and assesses to what extent the company has reached its goals. The company must specify a set of indexes that reflect its performance. These indexes can be quantitative or nonquantitative. For example, we can consider an index like the lead time as a quantitative (or financial) index, during the customer satisfaction is a qualitative (or nonfinancial) index. During performing BSC, directors have difficulty specifying strategies and selecting scales.

In the initial step of performing BSC, it is important to collect the possible ideas regarding the performance via interviewing business managers and discussing their vision, mission, and strategy. Meyer and Markiewicz [27] enclosed the vital factors of successful banking performance under categories: profitability, efficiency, human resources management, risk management, quality of services, capital management, and competition status.

Collier [7] employed the models of structural equations using such factors as quality process errors, employee turnover rate, labour productivity, on-time delivery, and the unit cost to analyze the process of bank performance. Arshadi and Lawrence [22] have used the multidimensional indexes such as profitability, the price of banking services, and the share of loan market. Most of previous studies have focused on the customer and what bank and what general services they choose. According to the relevant literature, the criteria upon which the customer evaluates and chooses the bank consists of price, ease of access, customer services, place, credibility and reliability, modern facilities, interest rates, working hours, incentive suggestions, the domain of product, and the policy of service price [28-32]. In their latest research, Devlin and Gerrard [32] tried to reveal the relative importance of different criteria for selecting banks using the quantitative statistical methodology. They provided the customers' choosing criteria and multiple banking and created the point by point comparison of the relative importance of the selection criteria vital to the selection of the primary and secondary banks.

2.3. Balanced Scorecard (BSC). Norton (the management director of Nolan Norton Institute) and Robert Kaplan (the Harvard University professor) suggested BSC in 1992. BSC specifies the organizational performance from the following four perspectives: financial, customer, internal business process, and learning and growth, which are in relation with the four following subordinates: accounting and financial, marketing, value chain, And human resources. We can use these financial and nonfinancial criteria to help directors and employees align with the outlooks of organizations from four perspectives. BSC makes directors ready for the applications of the necessary tools for a successful competitive strive [8].

In reality, current organizations accept the introduction of the BSC by Kaplan and Norton and the integration of financial and nonfinancial scales in specifying the performance of both profiting and nonprofiting organizations $[33,34]$. If they recognize the most appropriate scale for their need, they can save both time and money. Delicate 


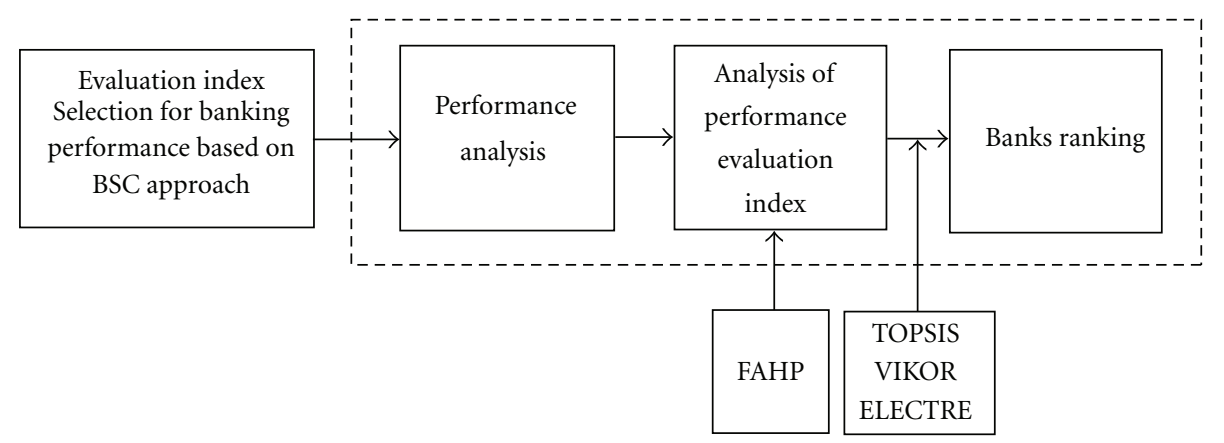

Figure 1: Performance evaluation framework of the research.

nonfinancial scales such as customer relations may be deemed more than half of the properties of a company. The important principle of the BSC is achieving success via the key nonfinancial factors after succeeding in key financial factors. These standards enable companies to manage their performance effectively and prognosticate their profits [6].

BSC is a general tool employed by many trades for assessing the performance in the different aspects. The advantages of using the BSC for banks are numerous. Some examples are the following: (1) usage of the BSC approach as a framework for the strategic assessment and development banks; (2) usage of the BSC approach for developing strategic goals and performance factors; (3) the approach is a way for specifying and supervising the performance of key stimulants that may lead to successful application of the bank's strategy; (4) the BSC approach is an effective tool to ensure the constant betterment of the bank's system and process [35]. Davis and Albright [3] presented an empirical analysis that investigated the effect of BSC on the financial performance of banks. Kim and Davidson [36] employed the BSC framework to assess the commercial performance of the Information Technology expenses in banking industry using the $t$-test and regression. Kuo and Chen [37] employed the four perspectives of the BSC via the fuzzy Delphi method to create performance assessment markers for stimulating the service industries. Leung et al. [38] suggested the custombuilt performance assessment model using AHP and ANP to establish the BSC.

A major part of the literature relevant to financial industries have employed and utilized the BSC for performance evaluation $[3,39]$. Much of these studies however, point to the need of creating an effective mechanism based on the relative weight for choosing assessment standards. Thus, this research develops a banking performance assessment model not only for investigating the relative importance among factors, but also for examining the delicate flaws to eliminate to reach the desired level.

\section{Research Framework and Analytic Methods}

Figure 1 explains the analytic structure of this paper. The performance analysis is based on the selective assessment standard. First, we have employed FAHP approach to calculate the relative weight of the performance assessment indexes. Then, we have utilized the multistandard analytic
TABLE 1: Membership function of linguistic scales.

\begin{tabular}{lcc}
\hline Linguistic scale & $\begin{array}{c}\text { Triangular fuzzy } \\
\text { scale }\end{array}$ & $\begin{array}{c}\text { Triangular fuzzy } \\
\text { reciprocal scale }\end{array}$ \\
\hline $\begin{array}{l}\text { Just equal } \\
\text { Equally } \\
\text { important }\end{array}$ & $(1,1,1)$ & $(1,1,1)$ \\
$\begin{array}{l}\text { Weakly } \\
\text { important }\end{array}$ & $(1,1,3)$ & $(1 / 3,1,1)$ \\
$\begin{array}{l}\text { Strongly } \\
\text { important }\end{array}$ & $(1,3,5)$ & $(1 / 5,1 / 3,1)$ \\
$\begin{array}{l}\text { Very strongly } \\
\text { important } \\
\text { Absolutely } \\
\text { important }\end{array}$ & $(3,5,7)$ & $(1 / 7,1 / 5,1 / 3)$ \\
\hline
\end{tabular}

tools of decision making consisting of TOPSIS, VIKOR and ELECTRE based on these weights to rate and ameliorate the banking performance and specify the best options.

3.1. Linguistic Variables at Fuzzy Set. According to Zadeh [40], a conventional quantification of reasonable expression in situations that are complex or hard to define is really difficult; in these cases the notion of a linguistic variable is vital. A linguistic variable defined as a variable whose values are words or sentences in a natural or artificial language. Here, we use five basic linguistic terms, for comparing the best plan evaluation criteria as "absolutely important," "very strongly important," "essentially important," "weakly important," and "equally important" according to a fuzzy five-level scale [11]. The membership function of a linguistic term is defined by Mon et al. [41] and displayed in Table 1.

We use linguistic variables to assess the performance value of alternative for each criterion as "very good," "good," "fair," "poor," and "very poor". A TFN fuzzy partition (see Figure 3 e.g.) is used to indicate the membership function of the expression values (Figure 2).

3.2. Fuzzy AHP. We summarize the procedure for determining the criteria weights in the FAHP method.

Step 1. Construct the pairwise comparison matrices among all the elements/criteria in the dimensions of the hierarchy system through expert questionnaire. Assign linguistic terms 


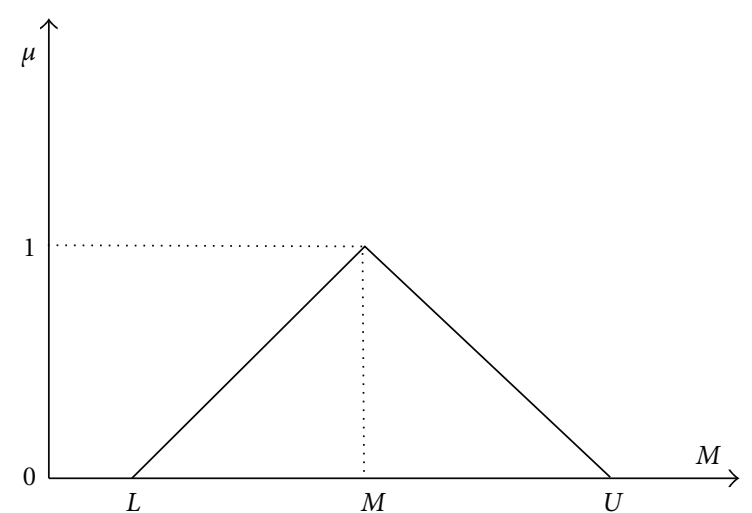

FIGURE 2: Hierarchical framework of research model based on BSC.

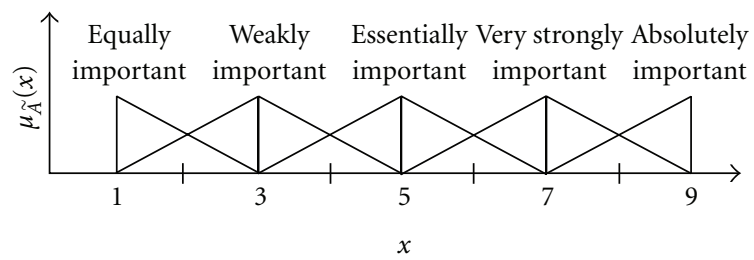

FIgURE 3: Membership function of a triangular fuzzy number.

by TFN to the pairwise comparisons by asking each expert its viewpoint elements/criteria, such as

$$
\widetilde{A}=\left[\begin{array}{cccc}
1 & \tilde{a}_{12} & \cdots & \tilde{a}_{1 n} \\
\tilde{a}_{21} & 1 & \cdots & \tilde{a}_{2 n} \\
\vdots & \vdots & \ddots & \vdots \\
\tilde{a}_{n 1} & \tilde{a}_{n 2} & \cdots & 1
\end{array}\right]=\left[\begin{array}{cccc}
1 & \tilde{a}_{12} & \cdots & \tilde{a}_{1 n} \\
1 / \tilde{a}_{21} & 1 & \cdots & \tilde{a}_{2 n} \\
\vdots & \vdots & \ddots & \vdots \\
1 / \tilde{a}_{n 1} & 1 / \tilde{a}_{n 2} & \cdots & 1
\end{array}\right] .
$$

Step 2. Compute the fuzzy geometric and compute the fuzzy weights of each criterion by normalization as Buckley [42] described as follows:

$$
\begin{aligned}
\tilde{r} & =\left(\tilde{a}_{j 1} \otimes \tilde{a}_{j 2} \otimes \cdots \otimes \tilde{a}_{i n}\right)^{1 / n}, \\
\tilde{w}_{i} & =\tilde{r}_{i}\left(\tilde{r}_{1} \otimes \cdots \otimes \tilde{r}_{n}\right)^{-1},
\end{aligned}
$$

where $\tilde{a}_{i n}$ is fuzzy comparison value of criterion $i$ to criterion $n$, thus, $\widetilde{r}_{i}$ is geometric mean of fuzzy comparison value of criterion $i$ to each criterion, $\widetilde{w}_{i}$ is the fuzzy weight of the $i$ th criterion, can be indicated by a TFN, $\widetilde{w}_{i}=\left(L w_{i}, M w_{i}, U w_{i}\right)$. Here $L w_{i}, M w_{i}$, and $U w_{i}$ stand for the lower, middle, and upper values of the fuzzy weight of the $i$ th criterion.

Bellman and Zadeh [10] were the first to propose the decision making problem in fuzzy environments and they announced the initiation of FMCDM. This analysis method has been widely applied to deal with DM problems involving multiple criteria evaluation/selection of alternatives in various fields. The practical applications reported in the literatures: weapon system evaluation [41], optimizating the design process of truck components [42]. These studies have shown the advantages obtained by handling unquantifiable/qualitative criteria and by applying this method obtained quite reliable results. According to a variety of subjective judgments among the experts' viewpoints, this research employs the overall valuation of fuzzy judgments to acquire more reasonable assessment. The following are the methods and procedures of the FMCDM theory.

(1) Alternatives Measurement. used the linguistic variables measurement to demonstrate the criteria performance (effect-values) by expressions such as "very good," "good," "fair," "poor," "very poor," which used the experts to express their subjective judgments, and a TFN within the scale range of $0-100$ for each linguistic variable. Assume $\widetilde{E}_{i j}^{k}$ to indicate the fuzzy performance value of evaluator $k$ towards alternative $i$ under criterion $j$ and indicate all of the evaluation criteria. Since the perception of each experts differs according to the evaluator's experience and knowledge, and the definitions of the linguistic variables vary as well, this study uses the concept of average value to integrate the fuzzy judgment values of $m$ evaluators, that is,

$$
\widetilde{E}_{i j}=\left(\frac{1}{m}\right) \otimes\left(\widetilde{E}_{i j}^{1} \oplus \widetilde{E}_{i j}^{2} \oplus \cdots \oplus \widetilde{E}_{i j}^{m}\right) .
$$

The sign $\otimes$ denotes fuzzy multiplication, the sign $\oplus$ indicates fuzzy addition, $\widetilde{E}_{i j}$ shows the average fuzzy number of the judgment of the decision makers, which a triangular fuzzy number has demonstrated as $\widetilde{E}_{i j}^{k}=\left(L \widetilde{E}_{i j}^{k}, M \widetilde{E}_{i j}^{k}, U \widetilde{E}_{i j}^{k}\right)$. The method put forward by Buckley [42] has computed the endpoint values $L E_{i j}, M E_{i j}$, and $U E_{i j}$, that is,

$$
L E_{i j}=\frac{\sum L E_{i j}^{k}}{m}, \quad M E_{i j}=\frac{\sum M E_{i j}^{k}}{m}, \quad U E_{i j}=\frac{\sum U E_{i j}^{k}}{m} .
$$

(2) Fuzzy Synthetic Decision. the calculation of fuzzy numbers has integrated the weights of each criterion of fuzzy performance values and was found at the fuzzy performance value of the basic evaluation. Regarding each criterion, FAHP has derived weight $\widetilde{w}_{j}$; the criteria weight vector $\widetilde{w}=\left(\widetilde{w}_{1}, \ldots, \widetilde{w}_{j}, \ldots, \widetilde{w}_{n}\right)^{t}$ can be acquired, whereas the fuzzy performance value of each alternative under $n$ criteria has attained the fuzzy performance matrix $\widetilde{E}$ of each of the alternatives, that is, $\widetilde{E}=\left(\widetilde{E}_{i j}\right)$. The vector $\widetilde{w}$ and fuzzy matrix $\widetilde{E}$ deduced the final fuzzy synthetic decision, and the obtained result is the fuzzy synthetic decision matrix $\widetilde{R}$, that is,

$$
\widetilde{R}=\widetilde{E} \odot \widetilde{w} .
$$

The sign " $\odot$ " indicates the computation of the fuzzy numbers, consisting of fuzzy addition and fuzzy multiplication. Since the calculation of fuzzy multiplication is somehow complicated, the result usually represents and the approximate fuzzy number $\widetilde{R}_{i}$, as $\widetilde{R}_{i}=\left(L R_{i}, M R_{i}, U R_{i}\right)$, where $L R_{i}$, 
$M R_{i}$, and $U R_{i}$, respectively, are the lower, middle, and upper synthetic performance values of the alternative $i$, that is,

$$
\begin{gathered}
L R_{i}=\sum_{j=1}^{n} L E_{i j} \times L w_{j}, \\
M R_{i}=\sum_{j=1}^{n} M w_{j} \times M E_{i j}, \\
U R_{i}=\sum_{j=1}^{n} U w_{j} \times U E_{i j} .
\end{gathered}
$$

(3) Ranking the Fuzzy Number. the result of the fuzzy synthetic decision obtained by each alternative is a fuzzy number. The procedure of defuzzification is to locate the Best Nonfuzzy Performance value (BNP) [12]. Methods utilized in such defuzzified fuzzy ranking usually include mean of maximal (MOM), center of area (COA), and $\alpha$-cut. The application of COA method is a simple and practical way to avoid the need to prefer some evaluators. Therefore, we utilize this method. The following formula calculates the BNP value of the fuzzy number $\widetilde{R}_{i}$ :

$$
\mathrm{BNP}_{i}=\left(\frac{\left[\left(U R_{i}-L R_{i}\right)+\left(M R_{i}-L R_{i}\right)\right]}{3}\right)+L R_{i}, \quad \forall i .
$$

According to the value of the derived BNP for each alternative, the ranking of each of the alternatives and criteria can then proceed.

3.3. TOPSIS. TOPSIS (Technique for Order Preference by Similarity to Ideal Solution) is one of the practical MADM techniques to solve real-world problems [43]. TOPSIS method was firstly suggested by Hwang and Yoon [44]. Based on this technique, the best alternative would be the one that has nearest distance to the positive ideal solution and farthest distance from the negative ideal solution [45]. The positive ideal solution has been defined as a solution that maximizes the benefit criteria and minimizes the cost criteria, whereas the negative ideal solution maximizes the cost criteria and minimizes the benefit criteria [46]. Briefly, all best values attainable of criteria have composed the positive ideal solution, whereas all worst values obtainable of criteria has made up the negative ideal solution [47]. This paper has used TOPSIS method for determining the final ranking of the private banking sector with following steps.

Step 1. Normalizing decision matrix via (10):

$$
r_{i j}=\frac{w_{i j}}{\sqrt{\sum_{j=1}^{J} w_{i j}^{2}}}, \quad j=1,2,3, \ldots, J .
$$

Step 2. Forming weighted normalized decision matrix:

$$
i=1,2,3, \ldots, n, \quad v_{i j}=w_{i} \times r_{i j}, \quad j=1,2,3, \ldots, J .
$$

Step 3. Calculating positive ideal solution (PIS), and negative ideal solution (NIS):

$$
\begin{aligned}
& A^{+}=\left\{v_{1}^{+}, v_{2}^{+}, \ldots, v_{n}^{+}\right\}, \\
& A^{-}=\left\{v_{1}^{-}, v_{2}^{-}, \ldots, v_{n}^{-}\right\} .
\end{aligned}
$$

Step 4. Computing the distance of each alternative from PIS and NIS:

$$
\begin{gathered}
d_{i}^{+}=\sqrt{\sum_{j=1}^{n}\left(v_{i j}-v_{j}^{+}\right)^{2}}, \quad j=1,2, \ldots, J, \\
d_{i}^{-}=\sqrt{\sum_{j=1}^{n}\left(v_{i j}-v_{j}^{-}\right)^{2}}, \quad j=1,2, \ldots, J .
\end{gathered}
$$

Step 5. Determining the closeness coefficient of each alternative:

$$
C C_{i}=\frac{d_{i}^{-}}{d_{i}^{+}+d_{i}^{-}}, \quad i=1,2, \ldots, J .
$$

Step 6. Obtaining the ranking of alternatives by comparing $C C_{i}$ values.

3.4. VIKOR. Opricovic [48], Opricovic and Tzeng [49] developed VIKOR, the Serbian name: VlseKriterijumska Optimizacija I Kompromisno Resenje, means multicriteria optimization and compromise solution [50] that is a suitable tool to evaluate each alternative. Experts elaborated the VIKOR method for multicriteria optimization of the complicated systems [51]. This method concentrates on ranking and selecting from a set of alternatives and chooses compromise solutions for a problem with conflicting criteria, which can sustain the decision makers to obtain a best final decision. The concept of VIKOR is based on compromise (feasible) solution which is the closest to the ideal alternative, and a compromise means an agreement established by mutual concessions [52]. It introduces the multicriteria ranking index according to the special measure of "closeness" to the "ideal" solution [48].

According to Opricovic and Tzeng [51], the PLp-metric utilized has developed the multicriteria measure for compromise ranking as an aggregating function in a compromise programming method. The various $J$ alternatives have been described as $a_{1}, a_{2}, \ldots, a_{j}$. For alternative $a_{j}, f_{i j}$ denotes the rating of the $i$ th aspect, for example, $f_{i j}$ is the value of $i$ th criterion function for the alternative $a_{j} ; n$ is the number of criteria. Development of the VIKOR method started with the following form of $L_{p}-$ metric:

$$
L_{p i}=\left\{\sum_{j=1}^{n}\left[\frac{\left(f_{j}^{*}-f_{i j}\right)}{\left(f_{j}^{*}-f_{j}^{-}\right)}\right]^{p}\right\}^{1 / p}, \quad 1 \leq p \leq \infty ; i=1,2, \ldots, m .
$$

VIKOR method uses $L_{1, j}$ and $L_{\infty j}$ to formulate ranking measurement value. Also VIKOR interprets $L_{1, j}$ as "concordance" 


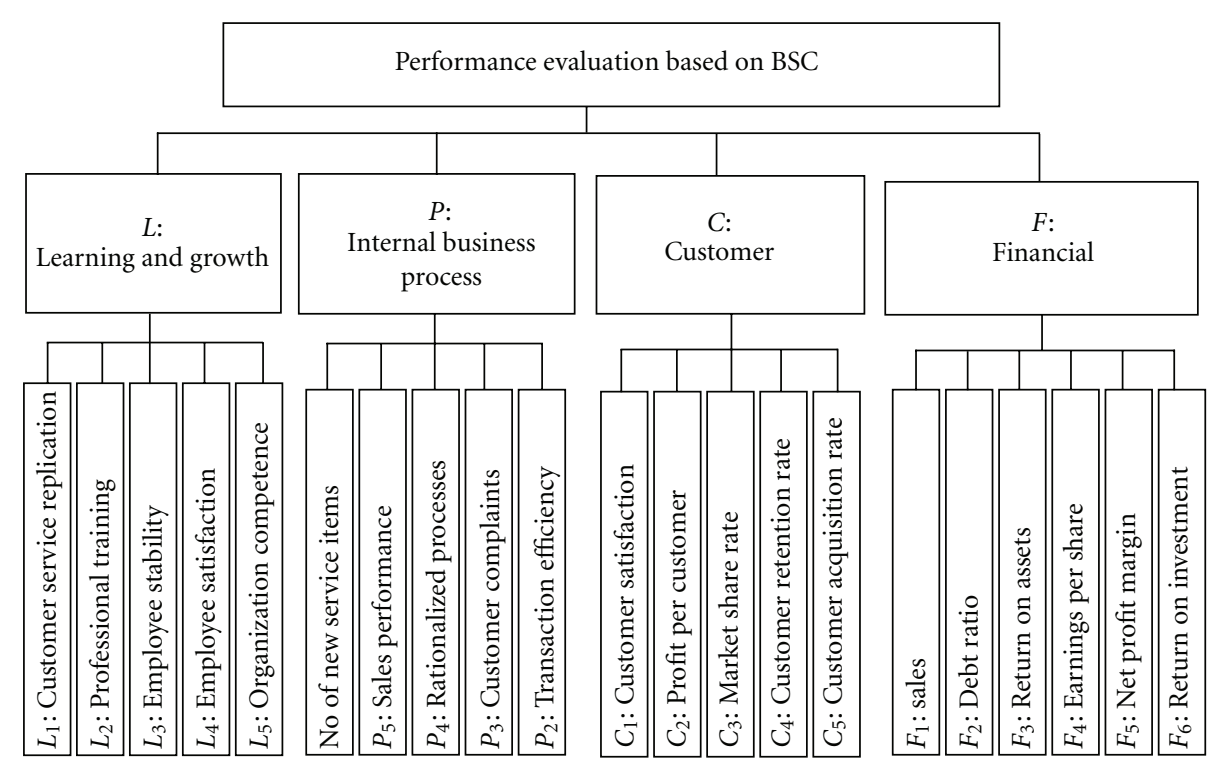

FIGURE 4: Membership function of linguistics variables for comparing two criteria.

and can contribute decision makers with information about the maximum group utility or "majority". Similarly, VIKOR interprets $L_{\infty j}$ as "discordance" and contributes decision makers with information about the minimum individual regret of the "opponent".

3.5. ELECTRE. The ELECTRE methodology is based on the concordance and discordance indices described as follows. First, the data of the decision matrix are defined, and the sums of the weights of all criteria equal to 1 are assumed. For an ordered pair of alternatives $\left(A_{j}, A_{k}\right)$, the concordance index $c_{j k}$ is the sum of all the weights for those criteria where the performance score of $A_{j}$ is least as high as that of $A_{k}$, that is.

$$
c_{j k}=\sum_{i: a_{i j} \geq a_{i k}}^{n} W_{i}, \quad j, k=1,2, \ldots, n, j \neq k .
$$

Vividly, the concordance index lies between 0 and 1 .

The calculation of the discordance index $d_{j k}$ is a little more complicated: $d_{j k}=0$ if $a_{i j}>a_{i k}, i=1, \ldots, m$, that is, the discordance index is zero if $A_{j}$ performs better than $A_{k}$ on all criteria. Otherwise,

$$
\begin{array}{r}
d_{j k}=\max _{i=1, \ldots, m} \frac{a_{i k}-a_{i j}}{\max _{j=1, \ldots, n} a_{i j}-\max _{k=1, \ldots, m} a_{i k}}, \\
j, k=1, \ldots, n, j \neq k,
\end{array}
$$

that is, for each criterion where $A_{k}$ outperforms $A_{j}$, the ratio is computed between the difference in performance level between $A_{k}$ and $A_{j}$ and the maximum difference in score on the criterion concerned between any pair of alternatives. The maximum of these ratios (which must lie between 0 and 1) is the discordance index. A concordance threshold $c^{*}$ and discordance threshold $d^{*}$ are then defined such that $0<d^{*}<c^{*}<1$. Then, $A_{j}$ outranks $A_{k}$ if the $c_{j k}>c^{*}$ and $d_{j k}<d^{*}$, that is, the concordance index is above and the discordance index is below its threshold, respectively.

This outranking described as a partial ranking on the set of alternatives. The set of all alternatives that outrank at least one other alternative are considered and are themselves not outranked. This set contains the promising alternatives for this decision problem. Interactively changing the level thresholds has shown changing in the size of this set.

The ELECTRE I method is utilized to construct a partial ranking and determine on a set of promising alternatives. ELECTRE II is applied for ranking the alternatives. In ELECTRE III an outranking degree is implemented, representing an outranking creditability between two alternatives which makes this method more [53].

\section{Assessing the Performance of the Private Banks of Iran}

We employ four perspectives as a framework for assessing the standards of performance (Figure 4). Based on this framework, the research uses the FAHP to weight the fuzzy indexes and utilizes the analytic tools TOPSIS, VIKOR, and ELECTRE to assess the performance of the banks based and to reduce the distance among the three banks.

4.1. BSC Performance Evaluation Criteria Framework. We summarize 51 indexes of the banking performance assessment by using four perspectives of the BSC and reviewing the related literature. we used a questionnaire to homogenize the proportions of the assessment indexes. A committee consisting of 12 academicians and 12 experiential banking experts has selected 21 assessment indexes. Figure 4 presents the hierarchical framework of performance assessment index of the BSC (4 perspectives and 21 indexes) for banking and their titles. We grouped these 21 assessment indexes in 4 BSC perspectives. The financial perspective consistss of 6 indexes 
TABLE 2: fuzzy weight of BSC performance indexes by FAHP.

\begin{tabular}{|c|c|c|c|c|c|}
\hline Criteria (dimension and index) & Local weights & Overall weights & $\mathrm{BNP}^{*}$ & Standard BNP** & Rank \\
\hline$F$ & $(0.137,0.192,0.273)$ & & 0.20 & 0.26 & 2 \\
\hline$F_{1}$ & $(0.211,0.293,0.411)$ & $(0.029,0.056,0.112)$ & 0.31 & 0.07 & 7 \\
\hline$F_{2}$ & $(0.164,0.222,0.310)$ & $(0.029,0.056,0.112)$ & 0.23 & 0.04 & 15 \\
\hline$F_{3}$ & $(0.229,0.330,0.475)$ & $(0.038,0.077,0.155)$ & 0.35 & 0.09 & 2 \\
\hline$F_{4}$ & $(0.235,0.333,0.471)$ & $(0.030,0.063,0.129)$ & 0.35 & 0.07 & 4 \\
\hline$F_{5}$ & $(0.210,0.308,0.437)$ & $(0.020,0.042,0.083)$ & 0.32 & 0.05 & 9 \\
\hline$F_{6}$ & $(0.229,0.312,0.424)$ & $(0.030,0.063,0.129)$ & 0.32 & 0.07 & 6 \\
\hline C & $(0.164,0.232,0.327)$ & & 0.24 & 0.32 & 1 \\
\hline$C_{1}$ & $(0.289,0.392,0.537)$ & $(0.048,0.091,0.176)$ & 0.41 & 0.11 & 1 \\
\hline$C_{2}$ & $(0.202,0.278,0.376)$ & $(0.033,0.065,0.123)$ & 0.29 & 0.07 & 5 \\
\hline$C_{3}$ & $(0.158,0.230,0.327)$ & $(0.022,0.044,0.089)$ & 0.24 & 0.05 & 8 \\
\hline$C_{4}$ & $(0.261,0.355,0.483)$ & $(0.034,0.067,0.132)$ & 0.37 & 0.08 & 3 \\
\hline$C_{5}$ & $(0.191,0.274,0.373)$ & $(0.018,0.038,0.075)$ & 0.28 & 0.04 & 11 \\
\hline$P$ & $(0.010,0.136,0.198)$ & & 0.18 & 0.23 & 3 \\
\hline$P_{1}$ & $(0.200,0.279,0.379)$ & $(0.019,0.039,0.076)$ & 0.29 & 0.05 & 10 \\
\hline$P_{2}$ & $(0.168,0.246,0.354)$ & $(0.013,0.028,0.056)$ & 0.26 & 0.03 & 17 \\
\hline$P_{3}$ & $(0.136,0.190,0.267)$ & $(0.013,0.026,0.051)$ & 0.20 & 0.03 & 18 \\
\hline$P_{4}$ & $(0.150,0.217,0.304)$ & $(0.012,0.024,0.048)$ & 0.22 & 0.03 & 19 \\
\hline$P_{5}$ & $(0.089,0.126,0.174)$ & $(0.012,0.024,0.047)$ & 0.13 & 0.03 & 20 \\
\hline$L$ & $(0.095,0.139,0.202)$ & & 0.15 & 0.19 & 4 \\
\hline$L_{1}$ & $(0.135,0.198,0.291)$ & $(0.011,0.022,0.046)$ & 0.21 & 0.03 & 21 \\
\hline$L_{2}$ & $(0.134,0.192,0.274)$ & $(0.018,0.037,0.075)$ & 0.20 & 0.04 & 12 \\
\hline$L_{3}$ & $(0.166,0.226,0.325)$ & $(0.016,0.031,0.066)$ & 0.24 & 0.04 & 13 \\
\hline$L_{4}$ & $(0.166,0.226,0.325)$ & $(0.015,0.031,0.060)$ & 0.23 & 0.04 & 16 \\
\hline
\end{tabular}

${ }^{*}$ BNP $($ Best nonfuzzy performance $)=[(U / L)+(M / L)] / 3+L$.

**STD_BNP: standardized BNP.

$\left(F_{1}-F_{6}\right)$, the customer perspective consist of 5 indexes $\left(C_{1}-C_{5}\right)$, the internal processes perspective has 5 indexes $\left(P_{1}-P_{5}\right)$, and the development and learning perspective has 5 indexes $\left(L_{1}-L_{5}\right)$ as well.

4.2. The Weight of Assessment Criterion. Based on the BSC hierarchical framework for the performance assessment index, we distributed the fuzzy AHP questionnaires which used Triangular Fuzzy Numbers (TNF) among the experts of the industry to achieve their expert opinion. Table 2 lists the relative importance (fuzzy weights) of each of the performance indexes by FAHP. The results reveal that the most important of the four perspectives is the customer perspective (0.315), and then is the financial perspective $(0.263)$, after that is the internal processes $(0.232)$, and the last is the development and learning (0.190). The five important assessment indexes consist of customer satisfaction $\left(C_{1}\right)$, return on assets $\left(F_{3}\right)$, customer retention rate $\left(C_{4}\right)$, earning per share $\left(F_{4}\right)$, and the profit per customer $\left(C_{2}\right)$, while the least important indexes are the customer service replication $\left(L_{1}\right)$, sales performance $\left(P_{5}\right)$, and the rational processes $\left(P_{4}\right)$.

4.3. Ranking of the Banking Performance. This research has taken three private Iranian banks (in abbreviation titles of S bank, P bank, and E bank) as an illustrative example and the experts have evaluated them based on the evaluation performance criterion. Although, there are differences of subjective judgments between experts' viewpoints and discretions, the overall employed evaluation of fuzzy judgments was combination of various mangers and experts opinions in order to achieve objective and comprehensive evaluation. We use the five linguistic variables, "very dissatisfied", "not satisfied", "fair", "satisfied," and "very satisfied" to measure the banking performance according to the evaluation criteria. A TFN presents each linguistic variable in a range of $0-100$. Various experts have integrated the average fuzzy judgment values of each criteria of the three banks and Table 3 presents this findings.

Then, the final fuzzy synthetic judgment of the three banks is deduced from the fuzzy criteria weights (Table 2) and the fuzzy judgment values (Table 3). Consequently, based on FAHP, we employed the three MCDM analytical tools TOPSIS, VIKOR, and ELECTRE, respectively, to rank the banking performance. Referring to Table 2, the paper has integrated the BNP values to average fuzzy judgments of various experts. Table 4 contains these results.

The relative closeness ( $\mathrm{RCi}$ ) to the ideal solution and evaluation result by TOPSIS is presented in Table 5. The relative closeness values for three banks are $\mathrm{E}$ bank $(\mathrm{RC}=$ 0.57), $\mathrm{P}$ bank $(\mathrm{RC}=0.515)$, and $\mathrm{S}$ bank $(\mathrm{RC}=0.481)$. 
TABLE 3: Average of fuzzy judgments value of experts.

\begin{tabular}{lccc}
\hline S bank & P bank & E bank & Indexes \\
\hline 69.44 & 73.33 & 81 & $F_{1}$ \\
50 & 70.8 & 62.15 & $F_{2}$ \\
49.75 & 60.89 & 50.5 & $F_{3}$ \\
61.25 & 45.9 & 78.63 & $F_{4}$ \\
68.6 & 57.54 & 64.42 & $F_{5}$ \\
60.33 & 70.35 & 73.67 & $F_{6}$ \\
60.69 & 70.81 & 79.33 & $C_{1}$ \\
64.6 & 70 & 68.63 & $C_{2}$ \\
61.33 & 67.60 & 70.33 & $C_{3}$ \\
59.75 & 63.63 & 71.60 & $C_{4}$ \\
55.5 & 53.25 & 72.43 & $C_{5}$ \\
67.83 & 61.53 & 74.6 & $P_{1}$ \\
64.75 & 66.33 & 70.12 & $P_{2}$ \\
62.63 & 60 & 59.41 & $P_{3}$ \\
56.53 & 71.7 & 68.30 & $P_{4}$ \\
75.33 & 69.34 & 52.13 & $P_{5}$ \\
70.33 & 66.67 & 75 & $L_{1}$ \\
71.94 & 59.66 & 80.81 & $L_{2}$ \\
50 & 55.85 & 60.33 & $L_{3}$ \\
53.30 & 79.44 & 72.50 & $L_{4}$ \\
74.66 & 65.33 & 71.70 & $L_{5}$ \\
\hline
\end{tabular}

TABLE 4: Indexes weight of three banks by FAHP.

\begin{tabular}{lccc}
\hline S bank & P bank & E bank & Indexes \\
\hline 0.54 & 0.57 & 0.63 & $F_{1}$ \\
0.47 & 0.66 & 0.58 & $F_{2}$ \\
0.52 & 0.65 & 0.54 & $F_{3}$ \\
0.56 & 0.42 & 0.76 & $F_{4}$ \\
0.62 & 0.52 & 0.58 & $F_{5}$ \\
0.49 & 0.75 & 0.60 & $F_{6}$ \\
0.55 & 0.56 & 0.62 & $C_{1}$ \\
0.55 & 0.60 & 0.58 & $C_{2}$ \\
0.57 & 0.63 & 0.52 & $C_{3}$ \\
0.56 & 0.53 & 0.63 & $C_{4}$ \\
0.53 & 0.50 & 0.69 & $C_{5}$ \\
0.57 & 0.52 & 0.63 & $P_{1}$ \\
0.56 & 0.57 & 0.60 & $P_{2}$ \\
0.60 & 0.57 & 0.57 & $P_{3}$ \\
0.50 & 0.63 & 0.60 & $P_{4}$ \\
0.57 & 0.60 & 0.45 & $P_{5}$ \\
0.57 & 0.54 & 0.61 & $L_{1}$ \\
0.58 & 0.48 & 0.65 & $L_{2}$ \\
0.52 & 0.58 & 0.63 & $L_{3}$ \\
0.45 & 0.66 & 0.60 & $L_{4}$ \\
0.61 & 0.53 & 0.59 & $L_{5}$ \\
\hline
\end{tabular}

These $\mathrm{RC}$ values mean that $\mathrm{E}$ bank has the smallest gap for achieving the desired level among the three banks, whereas the $S$ bank has the largest gap. Similarly, we used VIKOR to rank the banking performance based on the fuzzy weights
TABLE 5: The separa

\begin{tabular}{lcccc}
\hline Final ranking & $\mathrm{CL}$ & $\mathrm{d}_{\mathrm{i}}^{-}$ & $\mathrm{d}_{\mathrm{i}}^{+}$ & Banks \\
\hline 1 & 0.57 & 0.49 & 0.73 & E bank \\
2 & 0.51 & 0.52 & 0.49 & P bank \\
3 & 0.48 & 0.53 & 0.49 & S bank \\
\hline
\end{tabular}

TABLE 6: The performance matrix with the best value $x_{j}^{+}$and worst value $x_{j}^{-}$by VIKOR.

\begin{tabular}{lccccc}
\hline Indexes & bank S & bank P & bank E & $x_{i}^{-}$ & $x_{i}^{+}$ \\
\hline$F_{1}$ & 69.44 & 73.33 & 81.00 & 69.44 & 81.00 \\
$F_{2}$ & 50.00 & 70.80 & 62.15 & 50.00 & 70.80 \\
$F_{3}$ & 49.75 & 60.89 & 50.50 & 49.75 & 60.89 \\
$F_{4}$ & 61.25 & 45.90 & 78.63 & 45.90 & 78.63 \\
$F_{5}$ & 68.60 & 57.54 & 64.42 & 57.54 & 68.60 \\
$F_{6}$ & 60.33 & 70.35 & 73.67 & 60.33 & 73.67 \\
$C_{1}$ & 60.69 & 70.81 & 79.33 & 60.69 & 79.33 \\
$C_{2}$ & 64.60 & 70.00 & 68.63 & 64.60 & 70.00 \\
$C_{3}$ & 61.33 & 67.60 & 70.33 & 61.33 & 70.33 \\
$C_{4}$ & 59.75 & 63.63 & 71.60 & 59.75 & 71.60 \\
$C_{5}$ & 55.50 & 53.25 & 72.43 & 53.25 & 72.43 \\
$P_{1}$ & 67.83 & 61.53 & 74.60 & 61.53 & 74.60 \\
$P_{2}$ & 64.75 & 66.33 & 70.12 & 64.75 & 70.12 \\
$P_{3}$ & 62.63 & 60.00 & 59.41 & 59.41 & 62.63 \\
$P_{4}$ & 56.53 & 71.70 & 68.30 & 56.53 & 71.70 \\
$P_{5}$ & 75.33 & 69.34 & 52.13 & 52.13 & 75.33 \\
$L_{1}$ & 70.33 & 66.67 & 75.00 & 66.67 & 75.00 \\
$L_{2}$ & 71.94 & 59.66 & 80.81 & 59.66 & 80.81 \\
$L_{3}$ & 50.00 & 55.85 & 60.33 & 50.00 & 60.33 \\
$L_{4}$ & 53.50 & 79.44 & 72.50 & 53.50 & 79.44 \\
$L_{5}$ & 74.66 & 65.33 & 71.70 & 65.33 & 74.66 \\
\hline
\end{tabular}

TABLe 7: The $Q_{i}$ values with $v=0,0.5,1$ and preference order ranking by VIKOR.

\begin{tabular}{lccc}
\hline$Q_{i}(v=1)$ & $Q_{i}(v=0.5)$ & $Q_{i}(v=0)$ & Banks \\
\hline $0.42(1)$ & $0.39(1)$ & $0.36(1)$ & E bank \\
$0.44(2)$ & $0.43(2)$ & $0.41(2)$ & P bank \\
$0.49(3)$ & $0.47(3)$ & $0.43(3)$ & S bank \\
\hline
\end{tabular}

of the BSC performance evaluation indexes by FAHP as presented in Table 2.

Table 6 shows the performance matrix given with the best value $x_{j}^{+}$(aspired levels) and the worst value $x_{j}^{-}$(worst levels). Then, $Q_{i}$ values (with $v=0,0.5,1$ ) are computed and Table 7 shows the preference ranking order. The performance ranking order of the three banks by VIKOR in basic way $(v=0.5)$ is $\mathrm{E}$ Bank $\left(Q_{i}=0.398\right)>\mathrm{P}$ Bank $\left(Q_{i}=0.43\right)$ $>S$ Bank $\left(Q_{i}=0.471\right)$. The results of two other ways for computing $Q_{i}$ (with $v=0.5,1$ ) are the same as the basic one $(v=0.5)$.

Ultimately, the final values and preference order ranking by these two MCDM methods (TOPSIS and VIKOR) are 
TABLE 8: Summary of final preference order ranking by VIKOR and TOPSIS.

\begin{tabular}{lll}
\hline VIKOR & TOPSIS & Banks \\
\hline $0.39(1)$ & $0.57(1)$ & E bank \\
$0.43(2)$ & $0.51(2)$ & P bank \\
$0.47(3)$ & $0.48(3)$ & S bank \\
\hline
\end{tabular}

summarized in Table 8, which indicates that the ranking results by TOPSIS and VIKOR are identical. However, the normalized value in the VIKOR method does not depend on the assessment unit of a criterion function, while the vector normalization value at TOPSIS, may depend on the evaluation unit. TOPSIS introduces two reference points but it does not consider the relative importance of distances from these two points. VIKOR uses linear normalization but TOPSIS method uses vector normalization [51].

The last method is the ELECTRE (Elimination ET Choix Traduisant la REalité).This method is an outranking relations approach and Roy has developed this method in Europe. An outranking relation allows to conclude that an alternative outranks an alternative b if there are enough arguments to confirm that it is at least as good as b, while there is no essential reason to refuse this statement. To develop the outranking relation, the decision maker, in collaboration with the decision analyst, must specify the weights of the evaluation criteria, as well as some technical parameters (preference, indifference, and veto thresholds). The definition of these parameters enables the examination of whether there is a sufficient majority of criteria for which is better than $b$ (concordance) and if the unfavorable deviations for the rest of the criteria (discordance) are not too high. In this case it is possible to conclude that alternative outranks alternative b. Furthermore, through this modeling procedure it is possible to identify the cases where the performances of two alternatives on the evaluation criteria differ significantly, thus making impossible their comparison (incomparability). In first step in ELECTRE technique the indexes are normalized, as Table 9 shows as well and we utilized the weight of Tables 2 and 6 .

A concordance and discordance index set is first defined for every pair of alternatives

$$
\begin{aligned}
S_{12}= & \left\{F_{4}, F_{5}, C_{5}, P_{1}, P_{3}, P_{5}, L_{1}, L_{2}, L_{5}\right\}, \\
S_{13}= & \left\{F_{5}, P_{3}, P_{5}, L_{5}\right\}, \\
S_{21}= & \left\{F_{1}, F_{2}, F_{3}, F_{6}, C_{1}, C_{2}, C_{3}, C_{4}, P_{4}, L_{3}, L_{4}\right\}, \\
S_{23}= & \left\{F_{2}, F_{3}, C_{2}, P_{4}, P_{5}, L_{4}\right\}, \\
S_{31}= & \left\{F_{1}, F_{2}, F_{3}, F_{4}, F_{6}, C_{1}, C_{2}, C_{3}, C_{4}, C_{5}, P_{1}, P_{2},\right. \\
& \left.P_{4}, L_{1}, L_{2}, L_{3}, L_{4}\right\}, \\
S_{32}= & \left\{F_{1}, F_{4}, F_{5}, F_{6}, C_{1}, C_{3}, C_{4}, C_{5}, P_{1}, P_{2},\right. \\
& \left.L_{1}, L_{2}, L_{3}, L_{5}\right\} .
\end{aligned}
$$

Second, for each pair, the DM's weights for the corresponding concordance set are summed to arrive at a global concordance index

$$
\begin{aligned}
& I_{12}=W_{F 4}, W_{F 5}, W_{C 5}, W_{P 1}, W_{P 3}, W_{P 5}, W_{L 1}, W_{L 2}, W_{L 5} \\
& =0.041+0.03+0.023+0.026+0.018 \\
& +0.018+0.015+0.025+0.023=0.218 \text {, } \\
& I_{13}=W_{F 5}, W_{P 3}, W_{P 5}, W_{L 5} \\
& =0.03+0.018+0.018+0.023=0.089, \\
& I_{21}=W_{F 1}, W_{F 2}, W_{F 3}, W_{F 6}, W_{C 1}, W_{C 2} \text {, } \\
& W_{C 3}, W_{C 4}, W_{P 4}, W_{L 3}, W_{L 4} \\
& =0.037+0.024+0.059+0.04+0.061 \\
& +0.044+0.031+0.018+0.023=0.402, \\
& I_{23}=W_{F 2}, W_{F 3}, W_{C 2}, W_{P 4}, W_{P 5}, W_{L 4} \\
& =0.024+0.059+0.044+0.018 \\
& +0.017+0.023=0.184 \text {, } \\
& I_{31}=W_{F 1}, W_{F 2}, W_{F 3}, W_{F 4}, W_{F 6}, W_{C 1}, W_{C 2}, W_{C 3}, W_{C 4} \text {, } \\
& W_{C 5}, W_{P 1}, W_{P 2}, W_{P 4}, W_{L 1}, W_{L 2}, W_{L 3}, W_{L 4} \\
& =0.041+0.021+0.049+0.053+0.042 \\
& +0.068+0.043+0.032+0.049+0.030 \\
& +0.028+0.019+0.017+0.016 \\
& +0.028+0.024+0.021=0.582 \text {, } \\
& I_{32}=W_{F 1}, W_{F 4}, W_{F 5}, W_{F 6}, W_{C 1}, W_{C 3} \text {, } \\
& W_{C 4}, W_{C 5}, W_{P 1}, W_{P 2}, W_{L 1}, W_{L 2}, W_{L 3}, W_{L 5} \\
& =0.041+0.053+0.028+0.042 \\
& +0.068+0.032+0.049+0.030+0.028 \\
& +0.019+0.016+0.028+0.024+0.022=0.481 \text {, } \\
& I_{k l}=\left(\begin{array}{ccc}
- & 0.0218 & 0.089 \\
0.402 & - & 0.184 \\
0.582 & 0.481 & -
\end{array}\right), \quad \bar{I}=\frac{1.96}{6}=0.326 \text {, } \\
& H=\left(\begin{array}{ccc}
- & 0 & 0 \\
1 & - & 0 \\
1 & 1 & -
\end{array}\right) \\
& D_{12}=\left\{F_{1}, F_{2}, F_{3}, F_{6}, C_{1}, C_{2}, C_{3}, C_{4}, P_{4}, L_{3}, L_{4}\right\}, \\
& D_{13}=\left\{F_{1}, F_{2}, F_{3}, F_{4}, F_{6}, C_{1}, C_{2}, C_{3}, C_{4}, C_{5}\right. \text {, } \\
& \left.P_{1}, P_{2}, P_{4}, L_{1}, L_{2}, L_{3}, L_{4}\right\} \text {, } \\
& D_{21}=\left\{F_{4}, F_{5}, C_{5}, P_{1}, P_{3}, P_{5}, L_{1}, L_{2}, L_{5}\right\}, \\
& D_{23}=\left\{F_{1}, F_{4}, F_{5}, F_{6}, C_{1}, C_{3}, C_{4}, C_{5}\right. \text {, } \\
& \left.P_{1}, P_{2}, L_{1}, L_{2}, L_{3}, L_{5}\right\} \text {, } \\
& D_{31}=\left\{F_{5}, P_{3}, P_{5}, L_{5}\right\} \text {, } \\
& D_{32}=\left\{F_{2}, F_{3}, C_{2}, P_{4}, P_{5}, L_{4}\right\} \text {. }
\end{aligned}
$$


TABLE 9: Normalized data of indexes based on ELECTRE method.

\begin{tabular}{|c|c|c|c|c|c|c|c|}
\hline Indexes & S bank & P bank & E bank & Weight & S bank & P bank & E bank \\
\hline$F_{1}$ & 69.44 & 73.33 & 81.00 & 0.07 & 0.04 & 0.04 & 0.04 \\
\hline$F_{2}$ & 50.00 & 70.80 & 62.15 & 0.04 & 0.02 & 0.02 & 0.02 \\
\hline$F_{3}$ & 49.75 & 60.89 & 50.50 & 0.09 & 0.05 & 0.06 & 0.05 \\
\hline$F_{4}$ & 61.25 & 45.90 & 78.63 & 0.07 & 0.04 & 0.03 & 0.05 \\
\hline$F_{5}$ & 68.60 & 57.54 & 64.42 & 0.05 & 0.03 & 0.03 & 0.03 \\
\hline$F_{6}$ & 60.33 & 70.35 & 73.67 & 0.07 & 0.04 & 0.04 & 0.04 \\
\hline$C_{1}$ & 60.69 & 70.81 & 79.33 & 0.11 & 0.05 & 0.06 & 0.07 \\
\hline$C_{2}$ & 64.60 & 70.00 & 68.63 & 0.07 & 0.04 & 0.04 & 0.04 \\
\hline$C_{3}$ & 61.33 & 67.60 & 70.33 & 0.05 & 0.03 & 0.03 & 0.03 \\
\hline$C_{4}$ & 59.75 & 63.63 & 71.60 & 0.08 & 0.04 & 0.04 & 0.05 \\
\hline$C_{5}$ & 55.50 & 53.25 & 72.43 & 0.04 & 0.02 & 0.02 & 0.03 \\
\hline$P_{1}$ & 67.83 & 61.53 & 74.60 & 0.05 & 0.03 & 0.02 & 0.03 \\
\hline$P_{2}$ & 64.75 & 66.33 & 70.12 & 0.03 & 0.02 & 0.02 & 0.02 \\
\hline$P_{3}$ & 62.63 & 60.00 & 59.41 & 0.03 & 0.02 & 0.02 & 0.02 \\
\hline$P_{4}$ & 56.53 & 71.70 & 68.30 & 0.03 & 0.01 & 0.02 & 0.02 \\
\hline$P_{5}$ & 75.33 & 69.34 & 52.13 & 0.03 & 0.02 & 0.02 & 0.01 \\
\hline$L_{1}$ & 70.33 & 66.67 & 75.00 & 0.03 & 0.02 & 0.01 & 0.02 \\
\hline$L_{2}$ & 71.94 & 59.66 & 80.81 & 0.04 & 0.03 & 0.02 & 0.03 \\
\hline$L_{3}$ & 50.00 & 55.85 & 60.33 & 0.04 & 0.02 & 0.02 & 0.02 \\
\hline$L_{4}$ & 53.30 & 79.44 & 72.50 & 0.04 & 0.02 & 0.02 & 0.02 \\
\hline$L_{5}$ & 74.66 & 65.33 & 71.70 & 0.04 & 0.02 & 0.02 & 0.02 \\
\hline
\end{tabular}

Similarly, a global discordance index for each pair of alternatives is defined

$$
\begin{gathered}
N I_{12}=1, \quad N I_{13}=1, \quad N I_{21}=0.965, \\
N I_{23}=1, \quad N I_{31}=0.354, \quad N I_{32}=0.453, \\
N I_{k l}=\left(\begin{array}{ccc}
- & 1 & 1 \\
0.965 & - & 1 \\
0.354 & 0.453 & -
\end{array}\right), \\
\bar{N} I=\frac{4.807}{6}=0.801, \\
H=\left(\begin{array}{lll}
- & 0 & 0 \\
1 & - & 0 \\
1 & 1 & -
\end{array}\right), \\
F=\left(\begin{array}{ccc}
- & 0 & 0 \\
1 & - & 0 \\
1 & 1 & -
\end{array}\right)
\end{gathered}
$$

Finally, summery ranking by ELECTRE has represented in Table 10. Regarding Table 10, the final values of the three banks calculated ELECTRE are nearly close to TOPISIS, VIKOR results.

4.4. Gap Analysis Regard to Three Methods. Here we note that the final results that calculated TOPISIS, VIKOR, and ELECTRE are nearly close to each other. Based on literature
TABLE 10: Summary ranking by ELECTRE.

\begin{tabular}{lc}
\hline ELECTRE & Banks \\
\hline$(1)$ & E bank \\
$(2)$ & P bank \\
$(3)$ & S bank \\
\hline
\end{tabular}

of paper, TOPSIS and VIKOR are both based on relative closeness to ideal solution. While the VIKOR method introduces the ranking index based on the measure of closeness to ideal solution, TOPSIS method has chosen the alternative according to the "shortest distance" from the ideal solution and the "farthest distance" from the negative ideal solution. Totally, a comparative method between VIKOR and TOPSIS shows that they use different normalizations and introduce various aggregating functions for ranking the performance that may have different results. ELECTRE is the third method based on outranking relations approach. However the logic of VIKOR and TOPSIS is different from ELECTRE, but the result of all three methods is the same. In this case, the VIKOR and TOPSIS results are identical but VIKOR is a better method of assessment.

4.5. Discussion. We use a performance analysis on three banks by FMCDM approach based on the BSC perspectives. We adopt the FAHP and the three MCDM methods (TOPSIS, VIKOR and ELECTRE) in the performance, analysis for computing the fuzzy weights of the indexes, ranking the banking performance and improving the gaps between three 
banks. The results describe essential findings as follows. Here, the FAHP can not only involve the logical thought of human beings but also focuses on the relative importance of the evaluation criteria at the banking performance.

Based on Table 2 findings, the result of the FAHP analysis shows that the "Customer" dimension is the most significant dimension of the BSC and "customer satisfaction" is the most crucial evaluation index. Hence, in addition to paying attention to financial indexes like ROA and EPS, banks also must ensure that their customers remain loyal to them and develop new markets to attract new customers and sustain their retention. Therefore, based on the fuzzy weights of the evaluation criteria, the performance ranking order of the three banks using TOPSIS method is E Bank > P Bank $>\mathrm{S}$ Bank. The VIKOR ranking order result is the same as the TOPSIS and ELECTRE one. Furthermore, the result of VIKOR ranking is more precise and real in comparison to TOPSIS. When comparing the performance of S Bank with two other banks, as shown in Table 3, it is obvious that $S$ Bank has the lowest performance value in the "Customer" dimension while customer is the most critical BSC factor based onto the experts and managers views. As far as mentioned before, $\mathrm{S}$ Bank has the poorest performance value in the "market share rate" index too. It means that recognizing market share as a major factor in that bank's growth strategy is vital.

Therefore, S Bank should develop new service items and technology and/or provide more improved promotions to attract new clients in order to remain in banking industry besides retaining existing customers. So, $\mathrm{S}$ bank must first focuses on customer satisfaction and then on financial return.

\section{Conclusions}

By summarizing, we can say (1) the experts have integrated and has selected 21 evaluation indexes as the proper banking performance according to BSC perspectives; (2) by applying the FAHP, the ranking order of banking performance is as follow: " $C$ : Customer", " $F$ : Finance", " $P$ : Internal process," and " $L$ : Learning and growth." The top five ranking of the evaluation indexes are, respectively, " $C_{1}$ : Customer satisfaction", " $F_{3}$ : Return on assets", " $C_{4}$ : Customer retention rate," " $F_{4}$ : Earnings per share", and " $C_{2}$ : Profit per customer"; (3) ranking of the banking performance of the three banks by adopting the MCDM analytical tools as VIKOR, TOPSIS, and ELECTRE are E Bank, P Bank, and S Bank.

Thus we suggest that (1) although finding proper performance evaluation indexes to fit all experts and organization needs does not seem easy, we recommend tailoring the performance evaluation indexes to meet the organization's overall objective as well as individual goals. (2) We suggest to adopt the performance assessment indexes of the BSC perspectives which may not be mutually independent and other analytical methods like Analytic Network Process (ANP) to solve the interactive relationships among indexes. (3) We suggest to combine the other MCDM tools and several other techniques like Analytic Network Neuron (ANN) and FTOPSIS and compare their finding results. Fourthly, we suggest to utilize other performance evaluation techniques besides BSC like EFQM to achieve more suitable indexes. Finally we propose to investigate this approach in different industries such oil and gas, petrochemical, healthcare, and food for further validation.

\section{References}

[1] G. Dessler, Human ResourceManagement, Prentice-Hall, Upper Saddle River, NJ, USA, 8th edition, 2000.

[2] C. J. Pineno, "The balanced scorecard: an incremental approach model to health care management," Journal of Health Care Finance, vol. 28, no. 4, pp. 69-80, 2002.

[3] S. Davis and T. Albright, "An investigation of the effect of balanced scorecard implementation of financial performance," Management Accounting Research, vol. 15, no. 2, pp. 135-153, 2004.

[4] G. Lawrie and I. Cobbold, "Third-generation balanced card: evaluation of an effective strategic control tool," International Journal of Productivity and Performance Management, vol. 53, no. 7, pp. 611-623, 2004.

[5] R. S. Kaplan and D. P. Norton, "The balanced scorecard measures that drive performance," Harvard Business Review, vol. 70, no. 1, pp. 71-79, 1992.

[6] J. Mouritsen, H. T. Larsen, and P. N. Bukh, "Dealing with the knowledge economy: intellectual capital versus balanced scorecard," Journal of Intellectual Capital, vol. 6, no. 1, pp. 827, 2005.

[7] D. A. Collier, "Modelling the relationships between process quality errors and overall service process performance," International Journal of Service Industry Management, vol. 6, no. 4, pp. 4-19, 1995.

[8] R. S. Kaplan and D. P. Norton, "Using the balanced scorecard as a strategic management system," Harvard Business Review, vol. 74, no. 1, pp. 75-85, 1996.

[9] K. Kosmidou, F. Pasiouras, M. Doumpos, and C. Zopounidis, "Assessing performance factors in the UK banking sector: a multicriteria methodology," Central European Journal of Operations Research, vol. 14, no. 1, pp. 25-44, 2006.

[10] R. E. Bellman and L. A. Zadeh, "Decision-making in a fuzzy environment," Management Science, vol. 17, no. 4, pp. 141164, 1970.

[11] H. K. Chiou and G. H. Tzeng, "Fuzzy multiple-criteria decision-making approach for industrial green engineering," Environmental Management, vol. 30, no. 6, pp. 816-830, 2002.

[12] T. Y. Hsieh, S. T. Lu, and G. H. Tzeng, "Fuzzy MCDM approach for planning and design tenders selection in public office buildings," International Journal of Project Management, vol. 22, no. 7, pp. 573-584, 2004.

[13] H. K. Chiou, G. H. Tzeng, and D. C. Cheng, "Evaluating sustainable fishing development strategies using fuzzy MCDM approach," Omega, vol. 33, no. 3, pp. 223-234, 2005.

[14] C. T. Chen, C. T. Lin, and S. F. Huang, "A fuzzy approach for supplier evaluation and selection in supply chain management," International Journal of Production Economics, vol. 102, no. 2, pp. 289-301, 2006.

[15] T. C. Wang and T. H. Chang, "Application of TOPSIS in evaluating initial training aircraft under a fuzzy environment," Expert Systems with Applications, vol. 33, no. 4, pp. 870-880, 2007. 
[16] O. Bayazit and B. Karpak, "An analytical network processbased framework for successful total quality management (TQM): an assessment of Turkish manufacturing industry readiness," International Journal of Production Economics, vol. 105, no. 1, pp. 79-96, 2007.

[17] W. W. Wu and Y. T. Lee, "Selecting knowledge management strategies by using the analytic network process," Expert Systems with Applications, vol. 32, no. 3, pp. 841-847, 2007.

[18] A. H. I. Lee, W. C. Chen, and C. J. Chang, "A fuzzy AHP and BSC approach for evaluating performance of IT department in the manufacturing industry in Taiwan," Expert Systems with Applications, vol. 34, no. 1, pp. 96-107, 2008.

[19] G. Pépiot, N. Cheikhrouhou, J. M. Fürbringer, and R. Glardon, "A fuzzy approach for the evaluation of competences," International Journal of Production Economics, vol. 112, no. 1, pp. 336-353, 2008.

[20] R. G. Eccles, "The performance measurement manifesto," Harvard Business Review, vol. 69, no. 1, pp. 131-137, 1991.

[21] M. H. Qayoumi, Benchmarking and Organizational Change, APPA: The Association of Higher Education Facilities Officers, Alexandria, Va, USA, 2000.

[22] N. Arshadi and E. C. Lawrence, "An empirical investigation of new bank performance," Journal of Banking and Finance, vol. 11, no. 1, pp. 33-48, 1987.

[23] T. Gilligan, M. Smirlock, and W. Marshall, "Scale and scope economies in the multi-product banking firm," Journal of Monetary Economics, vol. 13, no. 3, pp. 393-405, 1984.

[24] P. Molyneux, Y. Altunbas, and E. P. M. Gardener, Efficiency in European Banking, John Wiley and Sons, London, UK, 1996.

[25] A. D. Athanassopoulos and D. Giokas, "The use of data envelopment analysis in banking institutions: evidence from the Commercial Bank of Greece," Interfaces, vol. 30, no. 2, pp. 81-95, 2000.

[26] L. Drake, "Efficiency and productivity change in UK banking," Applied Financial Economics, vol. 11, no. 5, pp. 557-571, 2001.

[27] D. W. Meyer and M. K. Markiewicz, "Developing a balanced scorecard at Wachovia Corporation," Bank Accounting and Finance, vol. 11, no. 1, pp. 13-19, 1997.

[28] W. Anderson Jr., J. E. P. Cox, and D. Fulcher, "Bank selection decisions and marketing segmentation," Journal of Marketing, vol. 40, no. 1, pp. 40-45, 1976.

[29] W. Boyd, M. Leonard, and C. White, "Customer preferences for financial services: an analysis," International Journal of Bank Marketing, vol. 12, no. 1, pp. 9-15, 1994.

[30] M. B. Elliot, D. Shatto, and C. Singer, "Three customer values are key marketing success," Journal of Retail Banking Services, vol. 18, no. 1, pp. 1-7, 1996.

[31] A. Chia and H. S. Hoon, "Adopting and creating balanced scorecards in Singapore-based companies," Singapore Management Review, vol. 22, no. 2, pp. 1-15, 2000.

[32] J. Devlin and P. Gerrard, "A study of customer choice criteria for multiple bank users," Journal of Retailing and Consumer Services, vol. 12, no. 4, pp. 297-306, 2005.

[33] D. Sinclair and M. Zairi, "An empirical study of key elements of total quality-based performance measurement systems: a case study approach in the service industry sector," Total Quality Management, vol. 12, no. 4, pp. 535-550, 2001.

[34] B. Ballou, D. I. Heitger, and R. Tabor, "Nonfinancial performance measures in the healthcare industry," Management Accounting Quarterly, vol. 5, no. 1, pp. 11-16, 2003.

[35] M. L. Frigo, P. G. Pustorino, and G. W. Krull, "The balanced scorecard for community banks: translating strategy into action," Bank Accounting and Finance, vol. 13, no. 3, pp. 1729, 2000.
[36] C. S. Kim and L. F. Davidson, "The effects of IT expenditures on banks' business performance: using a balanced scorecard approach," Managerial Finance, vol. 30, no. 6, pp. 28-45, 2004.

[37] Y. F. Kuo and P. C. Chen, "Constructing performance appraisal indicators for mobility of the service industries using fuzzy delphi method," Expert Systems with Applications, vol. 35, no. 4, pp. 1930-1939, 2008.

[38] L. C. Leung, K. C. Lam, and D. Cao, "Implementing the balanced scorecard using the analytic hierarchy process \& the analytic network process," Journal of the Operational Research Society, vol. 57, no. 6, pp. 682-691, 2006.

[39] C. Ashton, "Balanced scorecard benefits Nat West bank," International Journal of Retail and Distribution Management, vol. 26, no. 10, pp. 400-407, 1998.

[40] L. A. Zadeh, "The concept of a linguistic variable and its application to approximate reasoning," Information Sciences, vol. 8, no. 3, pp. 199-249, 1975.

[41] D. L. Mon, C. H. Cheng, and J. C. Lin, "Evaluating weapon system using fuzzy analytic hierarchy process based on entropy weight," Fuzzy Sets and Systems, vol. 62, no. 2, pp. 127-134, 1994.

[42] J. J. Buckley, "Ranking alternatives using fuzzy numbers," Fuzzy Sets and Systems, vol. 15, no. 1, pp. 21-31, 1985.

[43] K. Yoon and C. L. Hwang, "Manufacturing plant location analysis by multiple attribute decision making: part II. Multiplant strategy and plant relocation," International Journal of Production Research, vol. 23, no. 2, pp. 361-370, 1985.

[44] C. L. Hwang and K. Yoon, Multiple Attributes Decision Making Methods and Applications, Springer, Berlin, Germany, 1981.

[45] J. M. Benítez, J. C. Martín, and C. Román, "Using fuzzy number for measuring quality of service in the hotel industry," Tourism Management, vol. 28, no. 2, pp. 544-555, 2007.

[46] Y. M. Wang and T. M. S. Elhag, "Fuzzy TOPSIS method based on alpha level sets with an application to bridge risk assessment," Expert Systems with Applications, vol. 31, no. 2, pp. 309-319, 2006.

[47] Y. J. Wang, "Applying FMCDM to evaluate financial performance of domestic airlines in Taiwan," Expert Systems with Applications, vol. 34, no. 3, pp. 1837-1845, 2008.

[48] Opricovic, Multi-Criteria Optimization of Civil Engineering Systems, Faculty of Civil Engineering, Belgrade, Serbia, 1998.

[49] S. Opricovic and G. H. Tzeng, "Multicriteria planning of postearthquake sustainable reconstruction," Computer-Aided Civil and Infrastructure Engineering, vol. 17, no. 3, pp. 211-220, 2002.

[50] M. T. Chu, J. Shyu, G. H. Tzeng, and R. Khosla, "Comparison among three analytical methods for knowledge communities group-decision analysis," Expert Systems with Applications, vol. 33, no. 4, pp. 1011-1024, 2007.

[51] S. Opricovic and G. H. Tzeng, "Compromise solution by MCDM methods: a comparative analysis of VIKOR and TOPSIS," European Journal of Operational Research, vol. 156, no. 2, pp. 445-455, 2004.

[52] S. Opricovic and G. H. Tzeng, "Extended VIKOR method in comparison with outranking methods," European Journal of Operational Research, vol. 178, no. 2, pp. 514-529, 2007.

[53] M. Wu and T. Chen, "The ELECTRE multi criteria analysis approach based on intuitionist fuzzy sets," in Proceedings of the IEEE International Conference on Fuzzy Systems (FuzzIEEE '09), pp. 2-3, August 2009. 

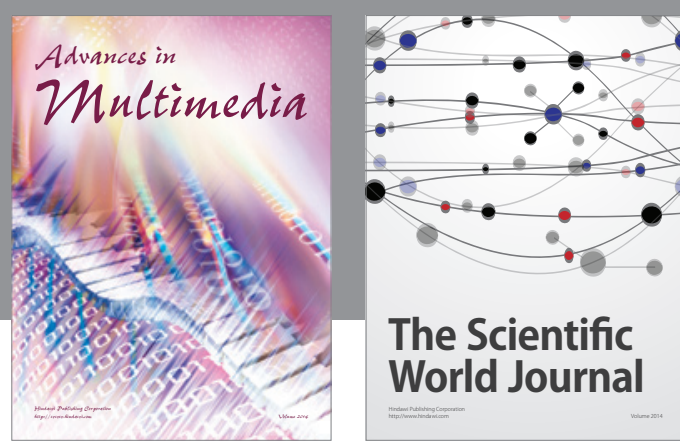

The Scientific World Journal
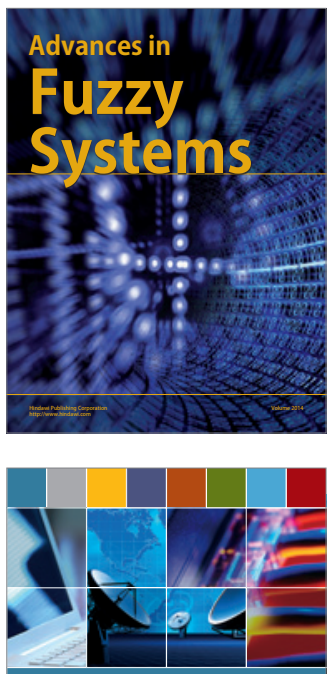

Computer Networks and Communications
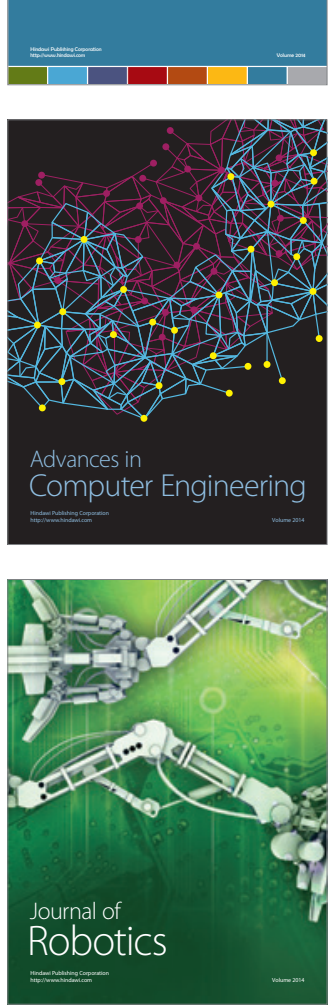
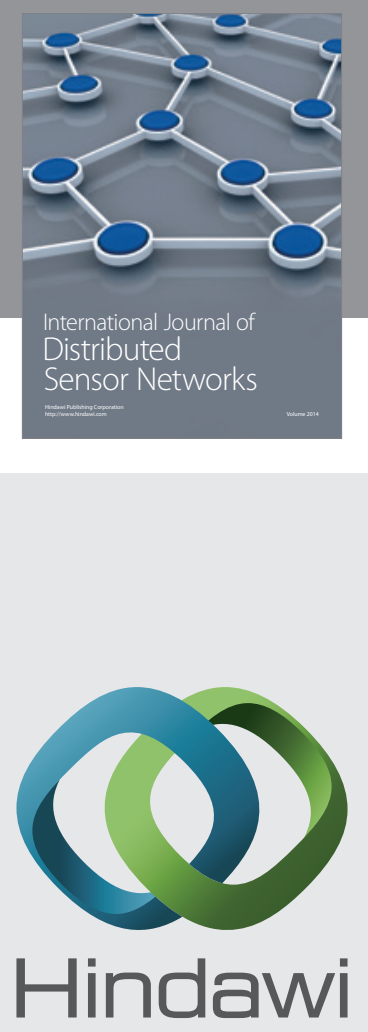

Submit your manuscripts at

http://www.hindawi.com
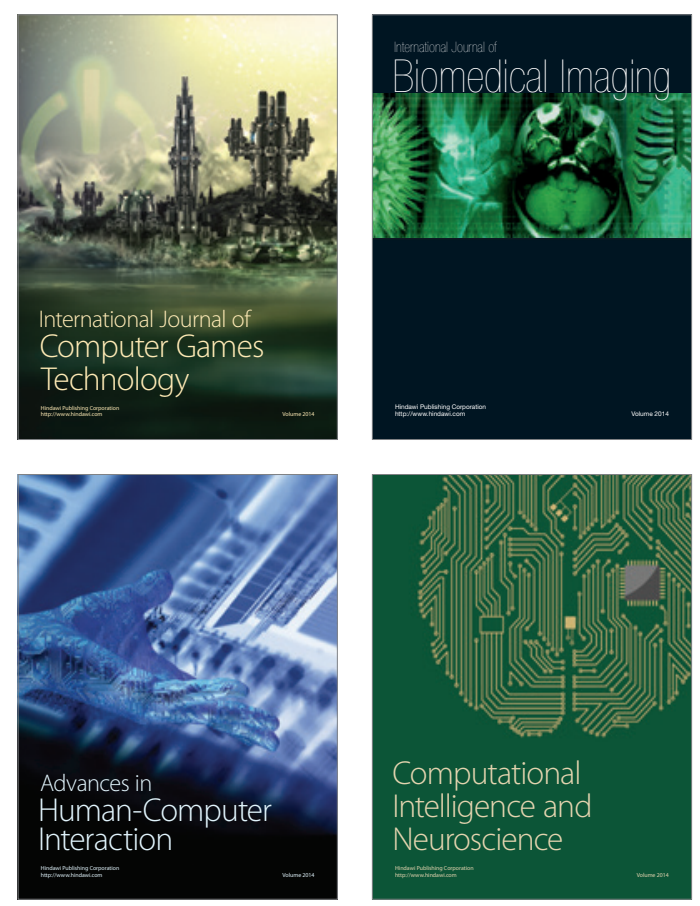
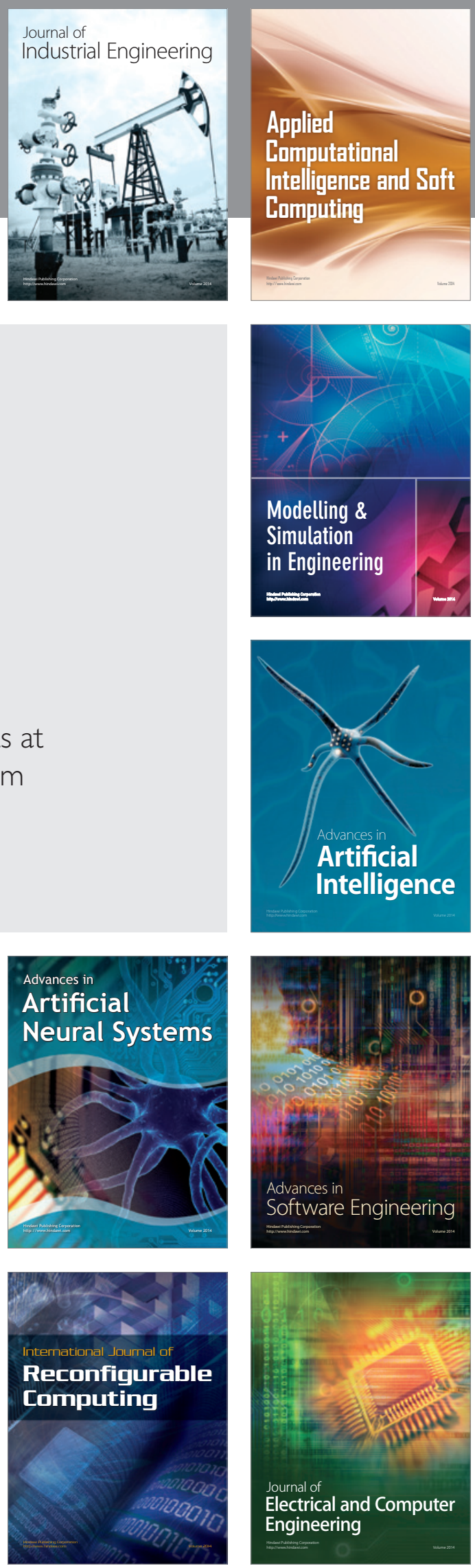